\title{
A CASE OF OSTEOPETROSIS (ALBERS-SCHÖNBERG) WITH INTERCURRENT PNEUMOCYSTIS PNEUMONITIS
}

\author{
BY \\ W. AHERNE \\ From the Department of Pathology, Radcliffe Infirmary, Oxford
}

(RECEIVED FOR PUBLICATION JANUARY 26, 1960)

\begin{abstract}
Albers-Schönberg $(1904,1907)$ defined the clinical and radiological features of a sclerosing disease of bone for which Karshner (1926) suggested the term osteopetrosis. As published cases of the disease accumulated, two types came to be distinguished (McCune and Bradley, 1934; Harnapp, 1937; Nussey, 1938; Zetterström, 1958). The first, or clinically 'malignant' type may be characterized by a refractory and often leucoerythroblastic anaemia, enlargement of liver, spleen and lymph nodes, a liability to multiple fractures, and death in infancy or early childhood. In the second or clinically 'benign' type, more commonly seen in adults, anaemia is mild and the osteosclerosis, though often severe, may yet be symptomless.
\end{abstract}

In the more severe forms of osteopetrosis, intercurrent infection, particularly of the respiratory tract, is a serious hazard. The case to be reported here, an example of the 'malignant' type, succumbed to an interstitial 'plasma cell' pneumonitis.

Though this unusual pneumonitis has been recognized for many years in central Europe its aetiology had been obscure until 1951. In that year Vaněk, in Czechoslovakia, identified Pneumocystis carinii in the lungs of all of a series of 16 fatal cases of this disease. In a series of papers (Vaněk, 1951 ; Vaněk and Jírovec, 1952; Vaněk, Jírovec and Lukeš, 1953) evidence was presented that Pneumocystis carinii was the causal agent of interstitial plasma cell pneumonitis. Nevertheless, Deamer and Zollinger (1953), who first drew American attention to the disease, concluded that it was probably a viral one; they dismissed a fungal or protozoal agent as unlikely. Baar (1955) reported the first case to be observed in England and subscribed to the hypothesis that Pneumocystis carinii was the pathogen. The subject is comprehensively reviewed by Gajdusek (1957).

Pneumocystis carinii pneumonitis has been found associated with congenital agammaglobulinaemia (Hutchison, 1955; Bird and Thomson, 1957;
Russell, 1959), cytomegalic inclusion disease (Baar, 1955; Hamperl, 1956), and neoplastic disease of the lympho-reticular tissue in both children and adults (Vaněk, 1952; Jírovec and Vaněk, 1954; Le Tan Vinh, 1954; Hamperl, 1956). Association with Albers-Schönberg's osteopetrosis has apparently not been reported before.

\section{Case Report}

W.T. (Reg. No. R.I. 250922), was a male infant, the first-born and only child of healthy unrelated parents. Pregnancy and labour had been uneventful. In the first 24 hours bruises were noticed on his upper lip and on several toes. These bruises disappeared within a few days. On the second day he regurgitated blood-flecked milk. Nothing further happened until the 13th day when another bruise appeared on his right leg and a small haematoma-like swelling was found on his umbilicus. As these subsided others appeared near the anus and over the chest wall. He became progressively paler.

On admission to hospital at 3 weeks of age, he was pale but reasonably vigorous and not acutely ill. He weighed $5 \mathrm{lb} .14 \mathrm{oz}$. There were bruises on the left chest, right thigh, right groin and umbilicus. A small abscess cavity was found close to the anus posteriorly. The liver was palpated about a finger breadth below the costal margin, and though the spleen was not palpable at first it could be tipped after four days and readily palpated within a week. Apart from these there were no unusual clinical findings.

Laboratory Investigations on Admission. $\mathrm{Hb} 45 \%$ (6.6 g./100 ml.); erythrocytes showed some anisocytosis and poikilocytosis; there were no Heinz bodies. Leucocytes $34,000 /$ c.mm. (blast cells 340 , promyelocytes 700 , myelocytes 1,400 , band forms 2,700 , segmented neutrophils 12,000 , eosinophils 700 , monocytes 3,400 , lymphocytes 13,000 ); reticulocytes $1 \cdot 0 \%$; normoblasts (occasionally in mitosis) $5 / 100$ leucocytes. There was, therefore, a severe leucoerythroblastic anaemia (Fig. 1). In addition, the platelet count (Lempert) gave 21,000/c.mm. (a proportion of which were abnormal giant forms) and the bleeding time (Ivy) was prolonged to 13 minutes. Clotting time (Dale and Laidlaw) was normal at $1 \mathrm{~min} .50 \mathrm{sec}$. and the 


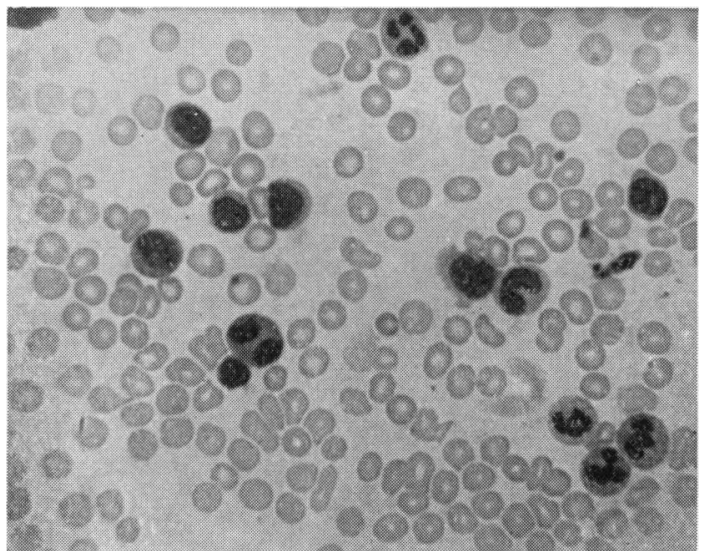

Fig. 1.-Peripheral blood film showing immature erythroid and myeloid cells. May-Gruenwald-Giemsa $\times 584$.

tourniquet test was negative. The blood group was $\mathrm{O} \mathbf{R h}$ positive. The direct Coombs test was negative and the mother's serum was found to be compatible with the patient's erythrocytes. No platelet agglutinins could be demonstrated in the mother's serum. The toxoplasma dye test dilution was $1 / 6$ and the toxoplasma complement fixation test was negative. Wassermann and Kahn reactions were negative in both mother and infant. Puncture of the tibial marrow was attempted unsuccessfully.

Progress in Hospital. Towards the end of the first week in hospital the perineal abscess was evacuated. A scalp vein transfusion of $110 \mathrm{ml}$. of blood brought the $\mathrm{Hb}$ level to $96 \%(14.2 \mathrm{~g}$. $/ 100 \mathrm{ml}$.). After this there was some clinical improvement, but within 17 days the $\mathrm{Hb}$ had fallen again to $58 \%(8.6 \mathrm{~g} . / 100 \mathrm{ml}$.$) , i.e. at the$ rate of about $2.6 \%(0.3 \mathrm{~g} . / 100 \mathrm{ml}$.) daily although there was no haemorrhage during this period. The fluctuations in the haemoglobin levels are shown in Fig. 2 in relation to blood transfusion and blood loss. Serial leucocyte and platelet levels are shown in the Table.

Further scalp-vein transfusion of $100 \mathrm{ml}$. of blood restored the $\mathrm{Hb}$ to $96 \%(14.2 \mathrm{~g}$./100 ml.). Five days later he developed epistaxis and began to ooze blood from the gums. About this time it was observed that any skin punctures tended to bleed excessively. During the next three weeks the $\mathrm{Hb}$ fell steadily to $46 \%(6 \cdot 8$ g./100 ml.) necessitating blood transfusion once again. A transfusion of $150 \mathrm{ml}$. was therefore given by an
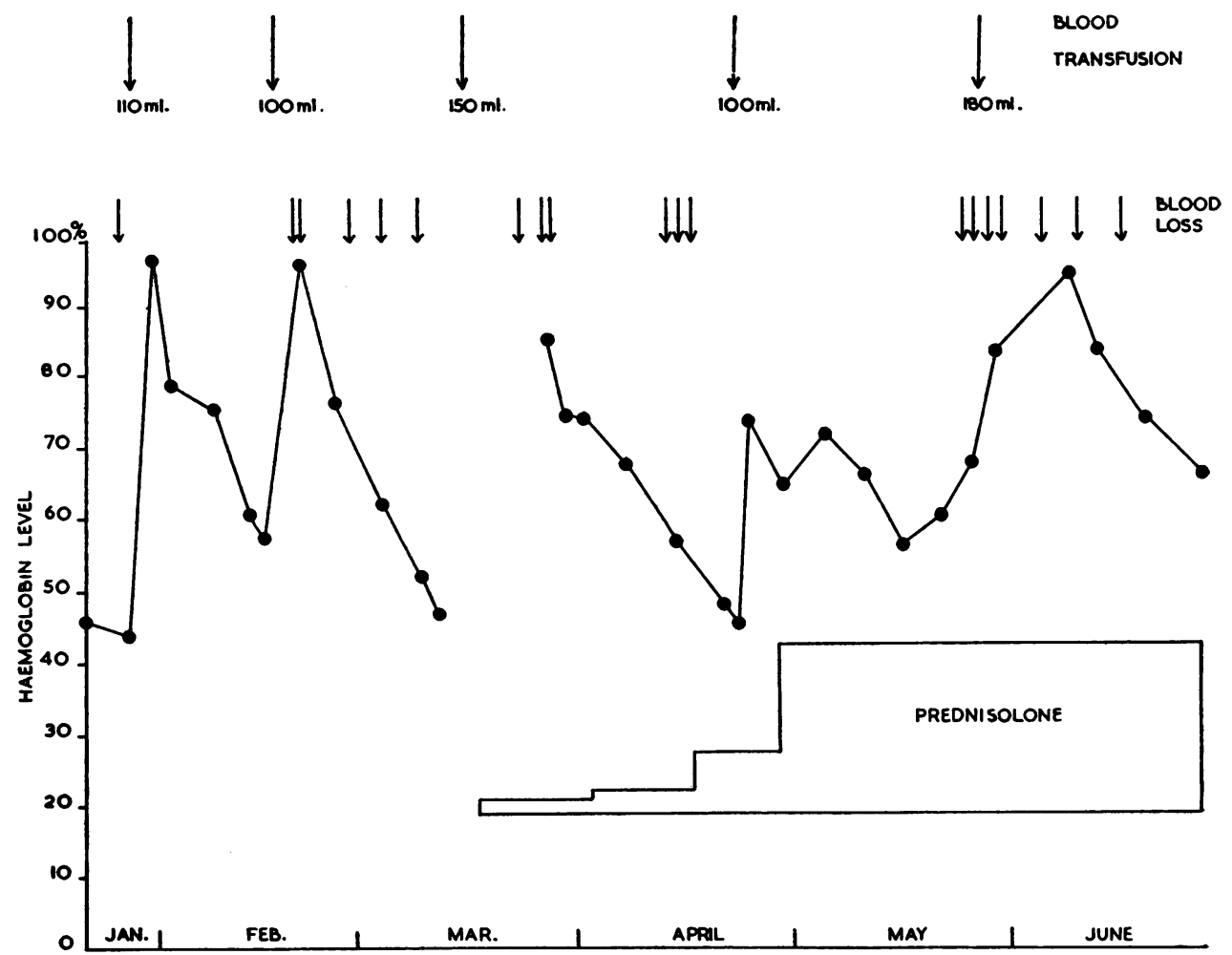

FIG. 2.-Serial haemoglobin levels. Blood transfusions and episodes of bleeding are arrowed. 
TABLE

SERIAL LEUCOCYTE AND PLATELET LEVELS

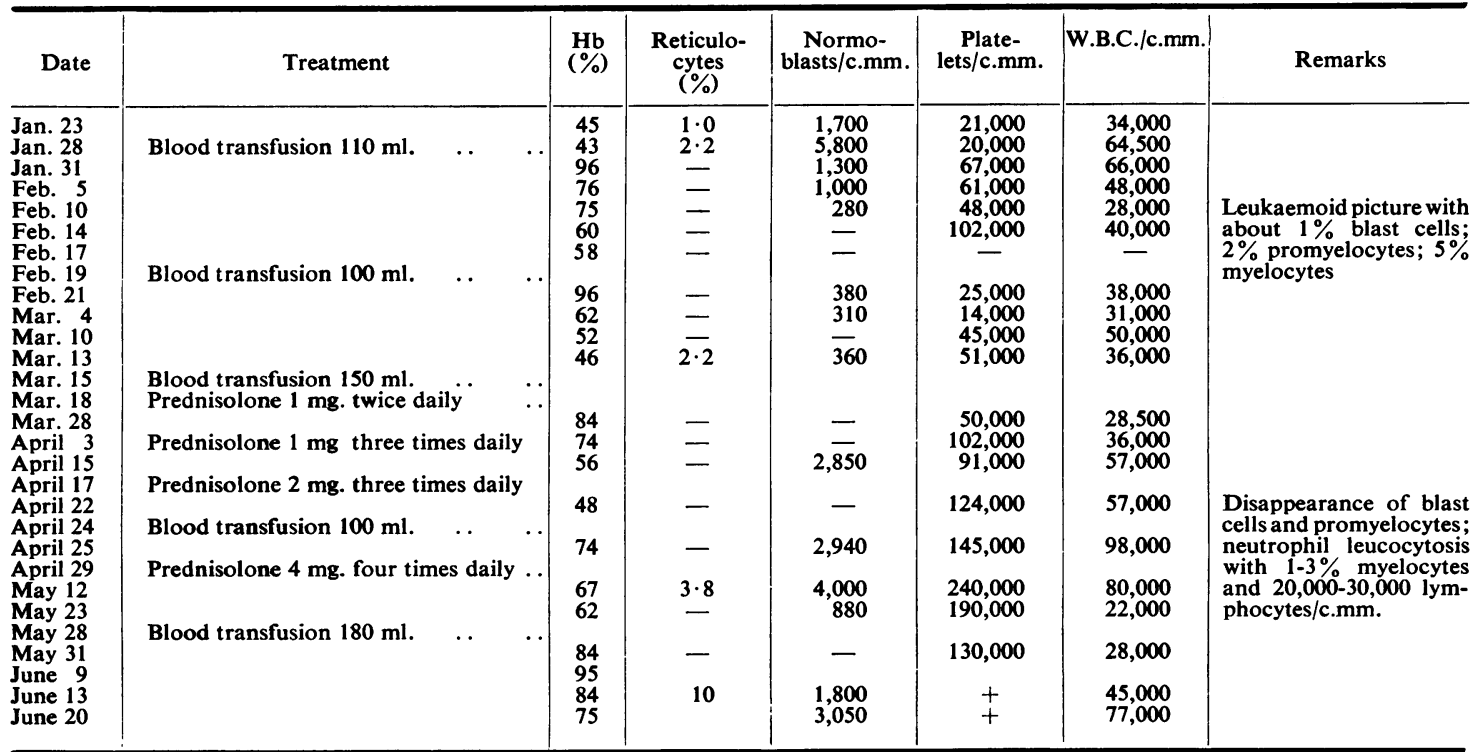

antecubital vein. Meanwhile the spleen was noted to be enlarging gradually. Septic skin lesions on the head and on the left hand were treated with oral terramycin.

Towards the end of the second month in hospital it was decided to treat him with prednisolone, at first in a dose of $1 \mathrm{mg}$. twice daily, increasing over the next four weeks to a maximum of $4 \mathrm{mg}$. four times a day. With this his general condition improved considerably, although he continued to show purpuric lesions over the skin and abdomen. The platelet count began to rise shortly after administration of prednisolone and reached the normal level of $240,000 / \mathrm{c} . \mathrm{mm}$. during the subsequent eight weeks.

Nevertheless, episodes of bleeding continued. Ten days after the start of prednisolone treatment severe epistaxis began again and continued in bouts during the next three weeks. It was eventually controlled by intranasal adrenaline sprays. By this time $\mathrm{Hb}$ level had fallen to $48 \%(7 \cdot 1 \mathrm{~g} . / 100 \mathrm{ml}$.), now at the rather slower rate of $1.4 \%$ daily. A further blood transfusion of $100 \mathrm{ml}$. was given.

Marrow puncture was attempted again and yielded, with some difficulty, a hypocellular but otherwise normal marrow. As a fortnight passed without blood loss, and he was in good general condition, he was discharged home on $16 \mathrm{mg}$. of prednisolone daily.

While at home he caught a 'cold' and developed a cough. He went off his feeds, which he had been taking well till then. He was therefore re-admitted, now at the age of $4 \frac{1}{2}$ months. On examination his temperature was $99 \cdot 6^{\circ} \mathrm{F}$. and his breathing rate was 64 per minute.
His colour was dusky and he looked ill. There was some nasal discharge and reddening of the fauces.

His breathing was grunting in character; the alae nasi were working and there was some intercostal recession. However, the percussion note and the breath sounds were normal and there were no adventitiae. The liver and spleen were still palpable but now smaller. A chest radiograph showed no definite radiological lesion.

Two days later there was a fresh crop of purpuric lesions on his abdomen, although his platelet count was now normal. He maintained a persistent low-grade fever with some cough but no physical signs in the chest. After a further transfusion of $180 \mathrm{ml}$. blood, which brought his $\mathrm{Hb}$ level from $62 \%(9.1 \mathrm{~g} . / 100 \mathrm{ml}$.) to $95 \%(14.1 \mathrm{~g} . / 100 \mathrm{ml}$.) his general condition improved though his breathing remained rapid and there was some further bleeding from nose and rectum. At this time the spleen had receded so that it could only be tipped. He was feeding well and seemed happy. He was discharged once again on prednisolone and oral erythromycin

He was re-admitted five days later because his cough had become worse and he had gone off his feeds again. On examination he was pale and ill and had a weak cry. His breathing was still rapid though his chest appeared clinically and radiologically clear. The liver was palpable two or three finger breadths below the costal margin; the spleen could not be felt. He remained somewhat febrile, breathing at the rate of $60-120 / \mathrm{min}$. On the 10th day of this admission he died suddenly at the age of 6 months. 
Morbid Anatomy. At autopsy (P.M. 512/58) the following were the main macroscopical findings:

\section{Macroscopical Findings}

Lungs. The lungs failed to retract as the chest was opened. Both were of a mottled café-au-lait colour. They presented a curious, vaguely nodular consolidation which was more marked in the lower lobes. The cut surfaces were dry and showed small scattered yellowishwhite areas. The tracheobronchial tree was normal.

Liver. The liver (196 g.) appeared normal in size, consistency and colour.

Spleen and lymphoid tissue. The spleen (16 g.) was rather firm, but not appreciably enlarged. The cut surfaces appeared normal. Lymph nodes in general were inconspicuous. The thymus was involuted.

Bones. The calvarium appeared to be of average thickness and density. The features of the base of the skull were not detectably abnormal and the middle ears were opened without difficulty. Both femora were shorter than normal and very slightly clubbed. They proved very difficult to cut because of a dense sclerosis of the medullae. A vertebral body was similarly sclerosed. These excised bones and the remainder of the skeleton were radiographed and showed the following features: There was an overall increase in the density of the femur as compared with a normal control (Fig. 3).

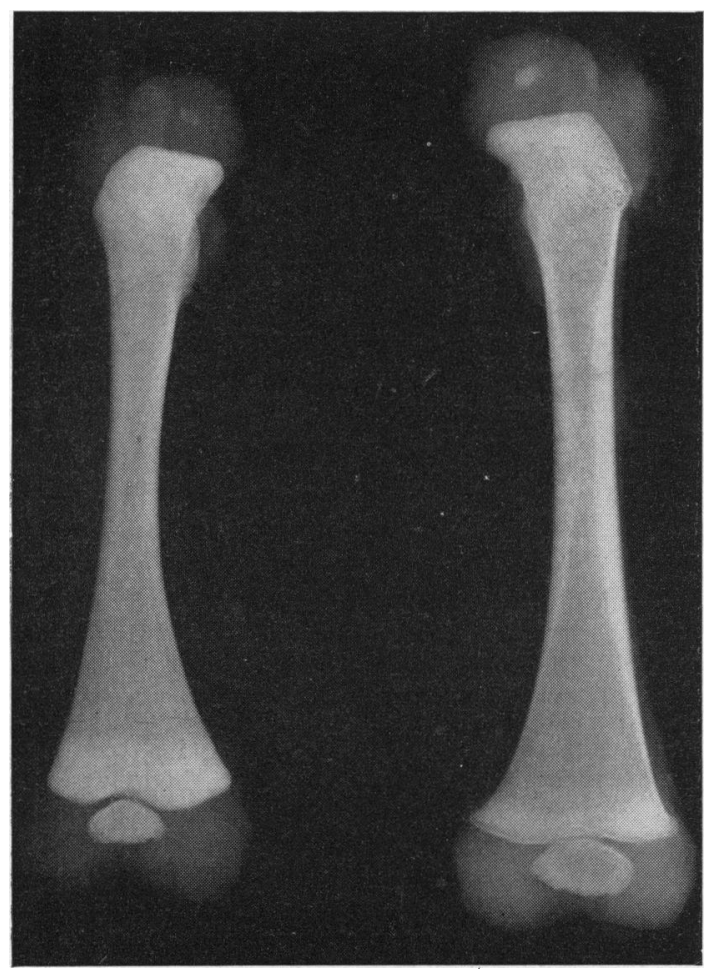

FIG. 3.-Femur showing osteopetrosis compared with normal femur of similar age.
Trabecular detail was obscured and marrow spaces appeared small. Particularly dense transverse bands occupied the metaphyseal growth zone; that in the distal metaphysis of the femur measured more than $1 \mathrm{~cm}$. in the axis of the bone. The distal epiphyseal centre of ossification was rather small and dense. Very similar changes were visible symmetrically in tibiae, fibulae, humeri, radii and ulnae. Clubbing was more obvious at the distal ends of the radii and the tibiae than elsewhere. Similar but slighter bands of metaphyseal density were visible in metacarpal bones. Pelvic bones, vertebrae, ribs, clavicles and scapulae showed some overall increase in density. In carpal, tarsal and skull bones the changes were too slight for dependable assessment.

\section{Histological Findings}

The Lungs. Both lungs showed an overall interstitial fibrosis. This was mainly due to an increase in reticulin but occasional collagen bundles contributed to it. The thickened alveolar walls and septa were infiltrated by mononuclear cells, some of which resembled plasma cells. Polymorphonuclear leucocytes were not seen in significant numbers. The alveoli and alveolar ducts in most areas contained an eosinophilic foamy material which was bordered in some alveoli by coalescing macrophages (Fig. 4). This material gave the tinctorial reactions of a polysaccharide (periodic acid-Schiff) through which small chromatin bodies (Giemsa: Feulgen) were distributed. It did not contain fibrin (Mallory's phototungstic acid-haematoxylin) or mucus (mucicarmine). Silver impregnation (Hortega) confirmed the presence of morphologically typical Pneumocystis carinii (Fig. 5). Viral studies were not made. The appearances were those of an interstitial pneumonitis in which the only detectable organism was the Pneumocystis carinii.

The Liver. The parenchymal cells contained rather large quantities of stainable iron.

The Spleen. The sinusoids were prominent and their littoral cells were plump. Many sinusoids contained large pale free macrophages. These phagocytes contained nuclei or fragments of nuclear material, a good deal of iron pigment and an occasional red cell ghost (Fig. 6). There was some excess of reticulin in the stroma. No evidence of haemopoiesis was found.

Lymph Nodes. These showed a fairly well marked excess of reticulin. Active haemopoiesis was visible in some nodes.

Bones. The disturbances affected endochondral ossification only mildly. Those seen in the femur will be taken as illustrative. Mutatis mutandis, similar changes were seen in other sites. The most striking feature was a massive persistence of calcified cartilage (the primary spongiosa) as irregular longitudinal islands, bordered and occasionally penetrated by immature new bone (Fig. 7). In the electron microscope the calcification of this cartilage was seen to be patchy but often unusually dense. The metaphyses were thus packed with stout anastomosing trabeculae of unresorbed primary elements and the enclosed marrow spaces were correspondingly small. This thicket extended in a modified form to the 


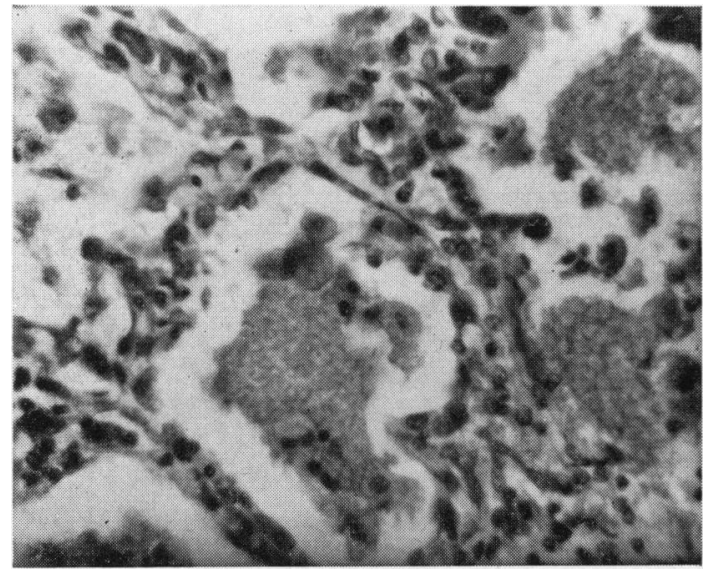

Fig. 4.-A group of pulmonary alveoli showing thickened alveolar walls and the foamy material of Pneumocystis carinii. H. and E. $\times 345$.

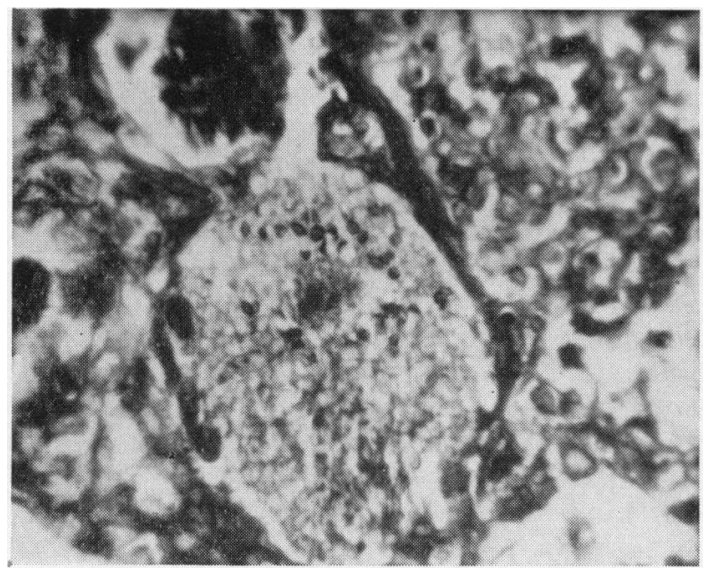

FIG. 5.-Pneumocystis carinii as demonstrated by silver impregnation. Hortega $\times 447$

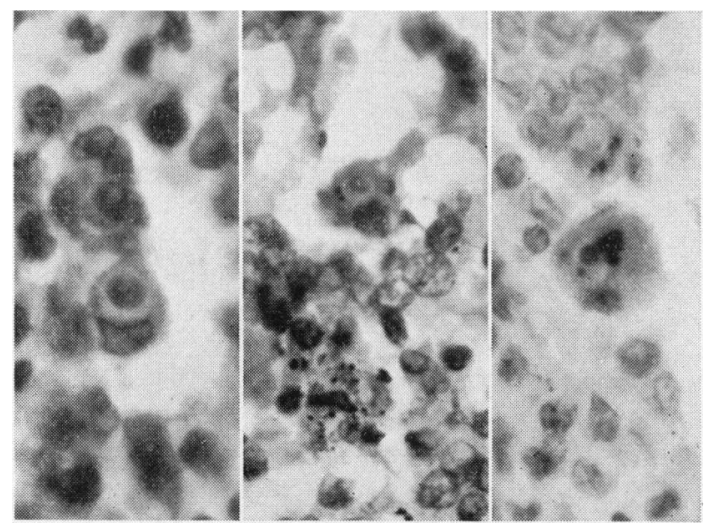

FIG. 6.-Composite picture of three splenic fields showing phagocytosis of a nucleated cell, an erythrocyte and some cell debris. H. and E. $\times 620$. diaphysis. Here spongy bone was still excessive but the cartilaginous component was diminished and the marrow spaces were considerably larger. In polarized light much of the new bone bordering the persistent cartilage showed normal lamellation. On the other hand the bone which had formed within vacated cartilage cell capsules showed no orientation of its collagen fibres. Both varieties of new bone were Schiff-positive.

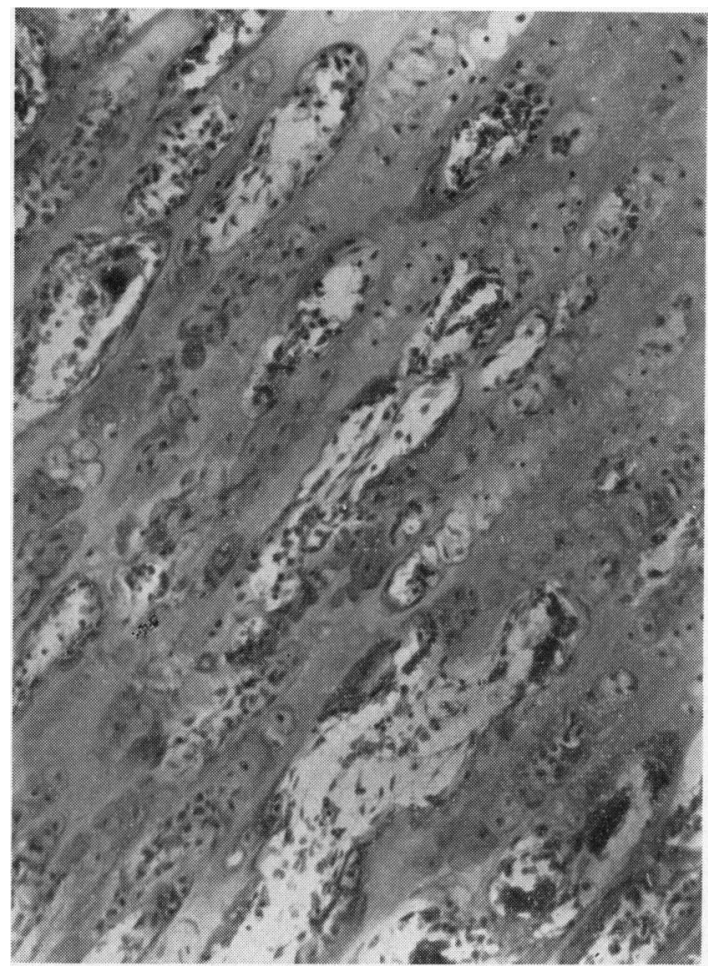

Fig. 7.-Metaphyseal growth zone of femur, showing abnormal persistence of cartilage and formation of dense chondro-osseous mosaic. H. and E. $\times 172$.

Periosteal ossification was less disturbed but Haversian systems appeared poorly formed in many areas. Occasionally the cortex included some persistent cartilage and immature bone.

Bone Marrow. The small marrow spaces in the growth zone contained an excess of reticulin through which ran thick-walled capillaries. Normal bone similarly stained showed more delicate mesenchyme and larger thin-walled vessels in this region. The osteopetrotic metaphysis appeared less vascular than usual and the capillaries morphologically abnormal.

Haemopoietic tissue occupied the marrow spaces in the remainder of the bone. Erythropoiesis and leucopoiesis were both in progress and occasional megakaryocytes were seen. There appeared to be a mild hyperplasia of myelocytes, and colonies of these cells were especially noted along the adventitia of small 
arterioles and along the borders of many trabeculae. Fat cells were very scanty. This marrow differed from normal marrow, similarly stained, in being more densely cellular and in not showing the usual prominence of marrow sinusoids. Where sinusoids could be discovered they contained both erythropoietic and leucopoietic cells, an appearance which suggested intravascular haemopoiesis.

Other Organs. Apart from some foci of calcium deposition in the medulla of the kidneys other organs were unremarkable.

$a_{1}$

\section{Discussion}

Generalized osteosclerosis in infancy may be secondary to congenital syphilis, heavy metal poisoning, excessive dosage with vitamin $\mathrm{D}$ and perhaps leukaemia. Of these diseases only leukaemia merits consideration in the present case. However, leukaemia typically causes osteolysis and on the rare occasions when it causes sclerosis this is found to be due to direct metaplasia of reticular or collagenous structures into woven bone (Windholz and Foster, 1949). Therefore this disease also may te ruled out.

Albers-Schönberg's osteopetrosis, on the other hand, accounts satisfactorily for both the clinical and the pathological findings. The clinical features closely resemble those of cases reported by Pines and Lederer (1947) and Turano, Fagan and Corbo (1954). The pathological structure of the bone is typical of osteopetrosis. As in previously reported cases the most obvious and probably the primary abnormality is a persistence of the calcified cartilaginous scaffolding upon which new bone is built. Layers of new Schiff-positive bone are seen on the surfaces of the cartilage masses, and tinctorially similar bone appears in the spaces from which cartilage cells have vanished. Normally a provisional design of this sort undergoes considerable modification. Most spongy bone and all remnants of cartilage are resorbed from the marrow cavity and increasingly lamellated bone is incorporated peripherally into the cortex. The appearances in the present case may be interpreted as the effect of a retarded remodelling process. Relatively little lamellar bone is present. Islands of immature bone, of which the collagen is unorientated, form a mosaic with the persistent irregularly calcified cartilage. The tensile strength of such tissue must be well below normal in spite of its apparent solidity.

Either the cartilage matrix is unusually resistant to remodelling or the mechanism of remodelling is defective. Of course, both factors may cooperate, but there is no evidence at present of abnormal cartilage matrix. On the other hand the vascular metaphyseal mesenchyme, which plays a major part in resorptive modelling, may well be at fault. Evidence in favour of this thesis may be found in the experimental work of Trueta and Amato (1960). They found that interruption of the blood supply to the metaphysis of growing bone inhibited the resorption of chondro-osseous tissue and delayed the formation of final bone. Large zones of calcified cartilage and preliminary bone remained at a level in the metaphysis where, normally, remodelling is taking place.

Many authors (McCune and Bradley, 1934; Lamb and Jackson, 1938; Clifton, Frank and Freeman, 1938; Pines and Lederer, 1947) have adopted Klemperer's (1931) suggestion that the fundamental disturbance in Albers-Schönberg's disease may lie in the undifferentiated mesenchymal anlage, the common progenitor of bone and marrow. Osteogenesis and haemopoiesis, according to this hypothesis, are both blighted by a prior defect involving mainly the former process in benign cases and the latter in malignant. But in the present case histological study did not suggest an intrinsic defect of osteogenesis. Similarly, Zetterström's (1958) biophysical studies led him to the conclusion that osteopetrotic bone comprises all those types of skeletal tissue which appear during the normal development of bone, the abnormality being a failure of normal removal. Furthermore, Pines and Lederer (1947) noted that the skeleton in general was poorly vascularized but that bone and marrow approached normal at sites of enhanced vascularity. In the present case also an impression of poor skeletal vascularity and of abnormal vessel structure was gained. The hypothesis of mesenchymal perversion might therefore be restated in a form which postulates abnormal vasoformation rather than abnormal osteogenesis. This view would suppose a mesenchymal defect which may involve predominantly the vascular remodelling tissue in benign osteopetrosis or the closely allied haemopoietic tissue in malignant osteopetrosis.

As in the cases of Lamb and Jackson (1938), Kramer and Halpert (1939), and others, the refractory anaemia could certainly not have been due to a simple crowding out of otherwise healthy haemopoietic tissue, as is commonly supposed to happen. In the present case the volume of the marrow cavity was estimated and found to be fully $70 \%$ of normal. Moreover, the marrow tissue was a good deal more cellular than normal. Therefore a merely mechanical theory of dyshaemopoiesis is plainly inadequate.

Though one may hypothetically attribute the leucoerythroblastic anaemia to a dysplasia of 
marrow tissue other mechanisms must also be evaluated. Skin sepsis and episodic haemorrhage must have played their parts, though the haemoglobin level continued to fall on occasions when neither was operative. Red cell destruction probably played a major part. Zetterström (1958), using a radioactive chromium technique, found a mean red cell survival time of 35-40 days in one of his cases, a patient aged 10 years. With colleagues (Engfeldt, Karlberg and Zetterström, 1955) he found a shortened survival time of both native and donor cells in another patient aged 6 years, though this observation was not expressed quantitatively. He therefore suggested that the anaemia may be due to hypersplenism. Loeb, Moore and Dubach (1953) have found this to be true of certain cases of myelosclerosis; in these, splenectomy restored a shortened red cell survival time to normal. Sjölin (1959) reported four cases of malignant osteopetrosis in each of which accelerated red cell destruction was proved isotopically. Splenectomy improved the haemoglobin level in all cases, though the red cell survival time was not always restored permanently to normal. The platelet count, which had been low in all four cases, returned to normal and reticulocytosis diminished. The author concluded that hypersplenism was an important feature of malignant osteopetrosis.

Though no direct estimate of red cell survival was made in the present case the concept of hypersplenism is apposite. Admittedly a cellular marrow is not necessarily a productive one but the abundance of maturing cells, together with the presence of normoblasts in the peripheral blood and a continuous reticulocytosis, suggest that the anaemia was not wholly due to a failure of production. Furthermore, the steep fall of haemoglobin level ( $2 \cdot 6 \%$ daily before administration of prednisolone), the marked haemosiderosis of liver and spleen (partly due to transfusion, no doubt) and the apparently enhanced activity of splenic phagocytes suggest excessive destruction.

The leukaemoid reaction is commonly supposed to be an expression of extramedullary haemopoiesis, at least in part; immature cells escape into the blood stream more easily from ectopic sites in soft organs. But the extent of haemopoiesis in the tissues at autopsy was surprisingly slight, as in many previously reported cases (Reiche, 1929, quoted by McCune and Bradley, 1931; Pease, DeSanctis and Alter, 1931; Lamb and Jackson, 1938). An alternative cause may lie again in dysfunction of the bone marrow itself, for which the observed myelocytic hyperplasia and the apparently intrasinusoidal haemopoiesis afford some evidence.
The tendency to haemorrhage is not completely explicable by thrombocytopenia and may have had a thrombasthenic component. Siegel, Friedman and Schwartz (1957) reported a patient with osteogenesis imperfecta tarda and an associated haemorrhagic diathesis due to increased capillary fragility and abnormal platelet function. These authors believed that their case represented a congenital defect involving two tissues of mesenchymal origin, the osseous system and the platelets. In the present case morphologically abnormal (giant) platelets were present and the haemorrhagic tendency persisted after the total platelet count had returned to normal.

Treatment with prednisolone brought about some improvement in the child's general condition and appeared both to decelerate the fall of haemoglobin level and to correct the leukaemoid state. The sclerosing process in the skeleton, on the other hand, was not abated. This is surprising, in view of the experimental findings of Baker and Ingle (1948) that 11-oxysteroids inhibited the proliferation of cartilage cells and brought about a profound and general atrophy of osteoblasts, so that the resorbtion of metaphyseal trabeculae occurred more rapidly than their formation. One might have expected prednisolone to be the rational treatment of osteopetrosis.

Prednisolone may have predisposed to infection with Pneumocystis carinii by further depression of a naturally low resistance. The result was the development of an interstitial pneumonitis of a type usually found in premature weakly infants or complicating diseases of the lymphoreticular system. It is of interest, furthermore, that prior and current treatment with prednisolone did not inhibit the development of a marked interstitial pulmonary fibrosis.

Summary
A case of 'malignant' osteopetrosis is reported. The patient presented in the neonatal period suffering from a leuco-erythroblastic anaemia complicated by a haemorrhagic tendency, and died at the age of 6 months primarily of an interstitial/pneumonitis due to Pneumocystis carinii. An attempt is made to illustrate some of the problematical features of osteopetrosis. Future research might be directed towards studying the vascularity of the bone, evaluating the respective roles of dyshaemopoiesis and increased red cell destruction, and determining the adequacy of platelet function.

My thanks are due to Dr. Victoria Smallpeice for permission to publish this case, to Dr. A. H. T. RobbSmith and Professor J. Trueta for critical advice, to many colleagues for their stimulating views, and to 
Mrs. D. Jackson and Mr. E. L. Tugwell for the photographs.

\section{REFERENCES}

Albers-Schönberg, H. (1904). Röntgenbilder einer seltenen Knochenerkrankung, Aertzl. Verein., Hamburg, February 9, 1904 Münch. med. Wschr., 51, 365.

- (1907). Eine bisher nicht beschriebene Allgemeinerkrankung des Skelettes im Röntgenbild. Fortschr. Röntgenstr., 11, 261.

Baar, H. S. (1955). Interstitial plasmacellular pneumonia due to pneumocystis carinii. J. clin. Path., 8, 19.

Baker, B. L. and Ingle, D. J. (1948). Growth inhibition in bone and bone marrow following treatment with adrenocorticotrophin (ACTH). Endocrinology, 43, 422.

Bird, T. and Thomson, J. (1957). 'Pneumocystis carinii' pneumonia. Lancet, $1,59$.

Clifton, W. M., Frank, A. and Freeman, S. (1938). Osteopetrosis (marble bones). Amer. J. Dis. Child., 56, 1020.

Deamer, W. C. and Zollinger, H. U. (1953). Interstitial 'plasma cell' pneumonia of premature and young infants. Pediatrics, 12. 11 .

Engfeldt, B., Karlberg, P. and Zetterström, R. (1955). (Quoted by Zetterström.) Studies on the skeletal changes and on the etiology of the anaemia in osteopetrosis. Acta path. microbiol. scand. $36,10$.

Gajdusek, D. C. (1957). Pneumocystis carinii-etiologic agent of interstitial plasma cell pneumonia of premature and young infants. Pediatrics, 19,543.

Hamperl, H. (1956). (Quoted by Bird and Thomson.) Proceedings of the Pathological Society of Great Britain and Ireland. Manchester, July, 1956.

Harnapp, G. O. (1937). (Quoted by Nussey.) Zum Bilde der Marmorknochenkrankheit. Die familiäre, gutartige Form der diffusen Osteosklerose. Mschr. Kinderheilk., 69, 1.

Hutchison, J. H. (1955). Congenital agammaglobulinaemia. Lancet, $2,844$.

Jirovec, O., and Vaněk, J. (1954). (Quoted by Bird and Thomson.) Zur Morphologie der Pnetumocystis carinii und zur Pathogenese der Pneumocystis-Pneumonie. Zbl. allg. Path. path. Anat., 92, 424.

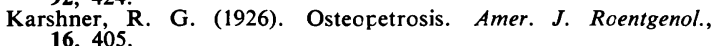

Klemperer, P. (1931). In discussion of paper by Pease, Desanctis and Alter, q.v.

Kramer, B. and Halpert, B. (1939). Marble bones. I. Clinicopathologic observations. Amer. J. Dis. Child., 57, 795.

Lamb, F. H. and Jackson, R. L. (1938). Osteopetrosis (marble bone disease). Amer. J. clin. Path., 8, 255.
Le Tan Vinh (1954). La pneumonie à pneumocystis; ses rapports avec la pneumonie interstitielle à plasmocytes. Arch. franç. Pédiat., 11, 1035 .

Loeb, V., Moore, C. V. and Dubach, R. (1953). The physiologic evaluation and management of chronic bone marrow failure. Amer. J. Med., 15, 499.

McCune, D. J. and Bradley, C. (1934). Osteopetrosis (marble bones) in an infant. Review of the literature and report of a case. Amer. J. Dis. Child., 48, 949.

Nussey, A. M. (1938). Osteopetrosis. Arch. Dis. Childh., 13, 161

Pease, M. C., DeSanctis, A. G. and Alter, N. M. (1931). AlbersSchoenberg's Disease. 'Marble-Bones'. Arch. Path. (Chicago), $11,509$.

Pines, B. and Lederer, M. (1947). Osteopetrosis: Albers-Schönberg disease (marble bones). Report of a case and morphologic study. Amer. J. Path., 23, 755.

Reiche, F. (1929). Quoted by McCune and Bradley (1931).

Russell, J. G. B. (1959). Pneumocystis pneumonia associated with agammaglobulinaemia. Arch. Dis. Childh., 34, 338.

Siegel, B. M., Friedman, I. A. and Schwartz, S. O. (1957). Haemorrhagic disease in osteogenesis imperfecta. Study of platelet functional defect. Amer. J. Med., 22, 315.

Sjölin, S. (1959). Studies on osteopetrosis. II. Investigation concerning the nature of the anaemia. Acta Paediat. (Uppsala) $48,529$.

Trueta, J. and Amato, V. (1960). The vascular contribution to osteogenesis: III. Changes in the growth cartilage caused by experimentally-induced ischaemia. J. Bone Jt Surg., (in the press).

Turano, A F. Fagan, K. A and Corbo, P. A. (1954). Variations in clinical manifestations of osteopetrosis. Report of two cases. J. Pediat., 44, 688.

Vaněk, J. (1951). (Quoted by Gajdusek.) Atypical interstitial pneumonia of infants produced by pneumocystis carpinii. Cas. Lék. Čes., 90, 1121.

(1952). (Quoted by Gadjusek and by Bird and Thomson.) Parasitic pneumonia due to pneumocystis carinii infection in a 60-year-old woman. Ibid., 91, 1260.

- and Jírovec, O. (1952). (Quoted by Gajdusek.) Parasitäre Pneumonie. 'Interstitielle' plasmazellenpneumonie de Frühgeborenen, verursacht durch Pneumocystis Carinii. Zbl. Bakt., 158 (I Abt.: Orig.), 120.

and Lukes, J. (1953). Interstitial plasma cell pneumonia in infants. Ann, paediat., 180, 1 .

Windholz, F. and Foster, S. E. (1949). Bone sclerosis in leukemia and in non-leukemic myelosis. Amer. J. Roentgenol., 61, 61.

Zetterström, R. (1958). Osteopetrosis (marble bones disease). Clinical and pathological review. Mod. Probl. Paediat., 3, 488. 